\title{
Whether Loyalty to a Football Club Can Translate into a Political Support for the Club Owner: An Empirical Evidence from Thai League
}

\author{
Thanaporn Sriyakul $^{1}$, Anurak Fangmanee ${ }^{2} \&$ Kittisak Jermsittiparsert $^{3,4}$ \\ ${ }^{1}$ Faculty of Business Administration, Mahanakorn University of Technology, Bangkok, Thailand \\ ${ }^{2}$ Khon Kaen United F.C., Khon Kaen, Thailand \\ ${ }^{3}$ Department for Management of Science and Technology Development, Ton Duc Thang University, Ho Chi \\ Minh City, Vietnam \\ ${ }^{4}$ Faculty of Social Sciences and Humanities, Ton Duc Thang University, Ho Chi Minh City, Vietnam \\ Correspondence: Kittisak Jermsittiparsert, Ton Duc Thang University, Ho Chi Minh City, Vietnam. E-mail: \\ kittisak.jermsittiparsert@tdt.edu.vn
}

Received: April 13, 2018

doi:10.5539/jpl.v11n3p47
Accepted: May 20, $2018 \quad$ Online Published: August 30, 2018

URL: https://doi.org/10.5539/jpl.v11n3p47

\begin{abstract}
The participation of politicians and their kin in the sport of football, as presidents of football clubs, in the past many years has been widely criticized as a use of the football clubs as tools to gain popularity and, possibly, a political base or a voting bloc for these politicians. This research is conducted in order to (1) study the loyalty level towards football clubs and the corresponding political supports expressed towards the football club executives and (2) examine the relationship between such demographic factors as gender, age, educational level, occupation, income, duration of being a fan, as well as loyalty to the football club and the aforementioned political supports, by collecting data from fans of five football clubs competing in the Thai League during the 2016 season. Including 385 fans, the data are collected using questionnaire, and then analyzed in terms of frequency, percentage, mean, standard variation, and Pearson's correlation coefficient analysis with the significance level set at five percent. The research finds that overall the fans of all five clubs are highly loyal to the club and express a moderate political support for the club executives. It also finds that gender, age, and education have no relationship to the political support, while occupation, income, duration of being a fan, and especially loyalty to the football club are correlated with the political support. This result confirms the hypothesis that loyalty to a football club can, in fact, potentially translate into a political support for the politicians who are also the owners of the football clubs.
\end{abstract}

Keywords: football club, Thai league, Politicians, loyalty, political support

\section{Introduction}

The research by Wasan Panyakaew, Arjin Tongyukong, Pongsakorn Sa-nguansak, and Plaifa Namprai (2016: 37-38) on "Thailand's Premier League: Masculinity, Adolescence, and Culture of Consumerism" and the research by Chalinee Sonphlay (2016a: 138-139) on "The Roles of Thai Politicians in a Thai Football Club: Business or Politics" indicate that "Thai League", as the top professional football league in Thailand, since it was established in 2009, has led to substantial changes in Thailand's professional football. The competition was formerly organized in the name of "Johnny Walker Thailand Soccer League" along with the "Provincial League", which, as seen from its inability to build a fan base, were not very successful. A survey of people in Bangkok in the areas near the football stadiums found that only 29.7 percent had attended a match. With this arose a saying that the football matches were "played among themselves and watched among themselves". A later expansion has, however, seen the number of stadium attendees increase consistently, from around 900,000 in 2009, and from 2010 to 2014, from 1.1 million, 1.3 million, 1.4 million, 1.6 million, to 1.9 million, respectively. These number did not include the number of TV audience, which has also consistently risen, as observed from the increase of broadcast fees from 40 million baht per year in 2009 to 200 million baht per year in 2011, 600 million baht per year in 2014, and more than 1 billion baht per year from 2017 on. 
The first research shows the survey result of NIDA Poll during the month of August 2015. Confirming the success of Thai League, the survey indicates that the Thai football fans following the Thai League football have increased in numbers, and the number has, for the first time, overtaken that following the English Premier League. The research also points for the readers to see that the fan culture at each football club reflects changes in the pattern of football consumption in the Thai society from being football fans who consume football via the television network to being football fans who feel close and tight-knitted with their favorite football clubs (Panyakaew, Tongyukong, Sa-nguansak, \& Namprai, 2016: 41-42). This is consistent with the latter research, which points to the force behind this important change. Having seen the changes, investing businesspeople respond by coming to support the football clubs at least in four ways. First, the football clubs have become channels of sales for their products on the competition days. Second, the football clubs have become channels to build awareness for their brands. Third, consumers who are fans of the football clubs tend to more easily support the products that lend support to the football clubs. Fourth, football clubs become tools to build image on social responsibility for any organizations (Sonphlay, 2016a: 139)

Interestingly, both pieces of research give the same indication that for investors from the political sector or the clan of politicians, it is unlikely that coming to own or support a professional football club is born from an economic incentive, because it is clear that managing a football club requires a large investment budget while often giving a return that is not very high or even creating losses (Sonphlay, 2016b: 139). Rather, the football clubs are viewed as a channel to build and preserve their voting bloc (Sonphlay, 2016a: 147). It is a channel to build an image and a new political space for the politicians after their political rights were taken away following the 2006 coup, such as the Chidchob family in case of the Buriram United Football Club, the Tiyapirach family in case of Chiangrai United, the Khunpluem in case of Chonburi, the Thepsutin family in case of Sukhothai, the Silpa-archa family in case of Suphan buri (Panyakaew, Tongyukong, Sa-nguansak, \& Namprai, 2016: 186).

This same conclusion can also be found in several Thai media. For example, in Matichon (2014)'s "Football and Politics" article, "Thai Football-World Cup Football: Sports, Merchandise, Populist Culture" concludes that "if football is rooted in the locality, then football fans will make connection with the political figures related to the team. In all, football is a powerful sport, which politicians hope to use as an instrument to reach out [to the people]. In teams with a politician serving as the president, the cheering will be done in ways that praise the president."

An article in Daily News (2014), “"Football” in the Front; "Politics" in the Back", finds that "in recent times, there has been an awakening in the football circles in Thailand as a result of Thai politicians jumping into the football business, which admittedly may be a by-product of their political rights having been taken away in the past many years. As many Thai politicians have become unemployed, they have to find a new toy as a way to establish reputation and voting bloc as well as to build their portfolio that can extend their names and keep them in people's memory." Along the same line, Komchadleuk's article (2016) on "People in Politics and Thai Football" "cannot refuse that football clubs are sources of power in building the popularity for politicians without risking committing illegal actions".

Although these suggestions are all consistent with comments made by Iranian experts) Dousti, Godarzi, Asadi, \& Khabiri, 2012( as well as experiences in such countries as Italy in case of A.C. Milan building a positive image for former Prime Minister Silvio Berlusconi )Semino \& Masci, 1996; Brazier, 2009: 71-73 (and France in case of Paris Saint-Germain F.C. during the 1995 election of former President Jacques Chirac (Ranc, 2009), they are all based on a descriptive analysis to convince the readers that loyalty to a football club, both psychologically and behaviorally, where each individual intrinsically tends towards a certain football club in addition to exhibiting repeated behaviors towards the club) Tokmak \& Aksoy, 2016: 86), can be translated for the club owners into a political support, the goals of which are to get elected and eventually become a local politician (Tantijariyapan, 2017: 5). However, since there has been no other research that adopts statistical tools to prove these suggestions empirically, this research aims to (1) study the level of loyalty to a football club and the level of political support to the politicians owning the club, and (2) test whether the hypothesis that demographic factors, especially the loyalty demonstrated by fans towards the football club are related to the political support demonstrated towards the politician owner of the club is true.

\section{Research Methodology}

\subsection{Population and Sample}

In the 2016 season of the Thai League, there were 18 football clubs participating in the competition, half of which could be considered a provincial-level club that is owned by a local politician. In order to limit and reduce the problem that may arise from the interpretation and the bias of this research team, the only football clubs 
selected here are those mentioned in the summary of the research by Panyakaew, Tongyukong, Sa-nguansak, and Namprai (2016: 186) as the cases where local bases have been built and invested in by former national-level politicians whose political rights have been taken away following the 2006 coup. These clubs include Buriram United, Chiangrai United, Chonburi FC, Sukhothai FC, and Suphanburi FC.

The population for this research, therefore, includes fans of the said five football clubs. The sample size is computed with the assumption that the population size is not known, using Cochran's formula (1977) at the confidence level of 95 percent and the margin of error of 5 percent. The resulting sample size is 385 . The sampling is then conducted using the quota method, whereby the number of fans selected for each club is equal, with 77 fans selected for each of the five clubs.

\subsection{Data Collection and Analysis}

Data are collected from fans of each football club based on a constructed questionnaire, which consists of three parts, including (1) demographic factors, such as gender, age, educational level, occupation, income, and duration he or she has been a fan, (2) loyalty to the football club measured by 12 questions, ranging from the basics such as their following of the club's news, their travelling to support the club at the stadium, their purchase of club souvenirs to their funding of the club's charity activities, and (3) political support given to the club owner measured by 12 questions addressing three dimensions, including four questions on their awareness of the club owner, four questions on their feeling towards the club owner, and four questions on the tendency for them to provide a political support to the club owner.

The attitude of fans in regards to their loyalty towards the football club and their political support for the club owner is measured in five-level Likert Scale, where 5 means the greatest loyalty or support and 1 means the least loyalty or support. The meaning of the average is interpreted according Boonchom Srisa-ard (2002).

The research team statistically analyzes the data in terms of frequency, percentage, mean, standard deviation, and Pearson's correlation coefficient analysis, with the statistical significance set at 0.05 level. The correlation coefficient analysis is interpreted according the criteria in Hinkle, William, and Stephen (1998).

\section{Research Framework}

Independent variable

\section{Dependent variable}

\section{Demographic factors}

1. Gender

2. Age

3.Educational level

4. Occupation

5. Income

6. Duration of being a fan

Political support provided to club owner

Loyalty to football club

Figure 1. Research framework

\section{Research Results}

\subsection{Demographic Factors}

Most of the samples in this survey are male (66.50 percent), at the age between 21 to 30 years $(39.20$ percent), with the education at the bachelor's level ( 48.30 percent), being employed in a private company ( 47.80 percent), and earning between 15,001 to 30,000 baht per year ( 46.50 percent). They have been a fan of one of the five football clubs in consideration for one to three years (45.20 percent).

\subsection{Loyalty to Football Club and Political Support to Club Owner}

Overall, the football fans in the sample are highly loyal to their club $(\bar{x}=3.56)$ even though they mainly only follow the news of the clubs, such as the ranking table $(\bar{x}=4.21)$, the competition program $(\bar{x}=4.19)$, the trade of players $(\bar{x}=4.00)$, and the purchase of club's jerseys $(\bar{x}=3.93)$. Still, they usually watch the match and root for the team via radio and television broadcasts $(\bar{x}=4.06)$ rather than going to the stadium to root for the team, whether it is a home game $(\bar{x}=3.51)$ or an away game $(\bar{x}=3.57)$.

The political support provided to the club owner is overall reported to be at the moderate level $(\bar{x}=3.49)$. When considering the support in various aspects, it is found that the fans are aware of the club owner and feel for 
the club owner at a high level $(\bar{x}=3.78 ; \bar{x}=3.53$ respectively $)$ while the potential political support for the club owners are only at the moderate level $(\bar{x}=3.17)$.

When asked whether the politician's participation in the football club has created a good reputation for the province, helped develop the province, improved the standard of the provincial team, and should be considered a sacrifice for the province, the answers tend to be a lot $(\bar{x}=3.86 ; \bar{x}=3.82 ; \bar{x}=3.78 ; \bar{x}=3.65$ respectively) along the same line as the way they appreciate the politician who manages their provincial football team to success and consider the said politician a good leader of the province $(\bar{x}=3.71 ; \bar{x}=3.65$ respectively).

However, when asked whether they feel indebted to the politician who help build a good reputation for the province, the answer is only moderate $(\bar{x}=3.20)$, which are along the same line as the propensity that they would support the politician, the family of the politician, or the subordinates of the politicians in a local election, a national election, and any other political activities $(\bar{x}=3.23 ; \bar{x}=3.15 ; \bar{x}=3.14 ; \bar{x}=3.16$ respectively).

\subsection{Hypothesis Testing}

The correlation coefficient analysis indicates that the demographic factors, including gender $(r=-.049)$, age $(\mathrm{r}=$ $-.043)$, and educational level $(\mathrm{r}=-.094)$, have almost no relationship with the political support given to the club owner. (The exception is the slightly negative relationship between the educational level and the behavioral tendency $(\mathrm{r}=-.119)$.)

Meanwhile, occupation and income are related to the political support given to the club owner in a very interesting way. Specifically, for occupation, the fans with relatively unstable jobs are more likely to lean in ways that favor the club owner or to report a greater political support to the club owner $(\mathrm{r}=.130$ and $\mathrm{r}=.117$ respectively). On the other hand, income is negatively correlated with the tendency and the political support that favor the club owner, which means that the lower the income, the more likely that such fans exhibit favorable behaviors or political supports towards the club owner $(r=-.175$ and $r=-.132$ respectively).

Also, the samples who have been fans for a longer period of time have less favorable feelings $(r=-.112)$, exhibit less favorable tendency $(r=-.157)$, and finally, exhibit less overall political support towards the club owners $(r=$ $-.130)$.

As for the hypothesis that the loyalty towards the football club is related to the political support given to the club owner, a weak positive correlation between the two is found, whether it is the relationship with the awareness of the club owner $(r=.394)$, the feeling towards the club owner $(r=.402)$, the tendency of showing a favorable behavior towards the club owner $(\mathrm{r}=.404)$, and eventually, the overall political support for the club owner $(\mathrm{r}$ $=.453)$.

Table 1. Relationship of demographic factors and loyalty to a football club with political support given to the club owner

\begin{tabular}{lllll}
\hline & Awareness & Feeling & Behavioral Tendency & Political Support \\
\hline Gender & -.038 & -.037 & -.055 & -.049 \\
Age & -.046 & .003 & -.068 & -.043 \\
Education & -.031 & -.090 & $-.119^{*}$ & -.094 \\
Occupation & .086 & .089 & $.130^{*}$ & $.117^{*}$ \\
Income & -.076 & -.087 & $-.175^{* *}$ & $-.132^{* *}$ \\
Length of fandom & -.065 & $-.112^{*}$ & $-.157^{* *}$ & $-.130^{*}$ \\
Loyalty & $.394^{* *}$ & $.402^{* *}$ & $.404^{* *}$ & $.453^{* *}$ \\
\hline
\end{tabular}

Remark: * means p-value $\geq .05 ; * *$ means p-value $\geq .01$.

\section{Conclusions and Discussions}

It has been widely critiqued that the participation of politicians and their kin in the sport of football as club owners in the past many years makes several football clubs in Thailand become voting blocs for various political groups. Not only does this research show that the fans of the five provincial Thai-league clubs that are owned by 
politicians are highly loyal to their respective club and moderately supportive of the respective club owner, but it also shows that the demographic factors, such as gender, age, and educational level, have no relationship with the political support given to the club owners.

An interesting observation from this research is the fans with unstable jobs or the ones with low income exhibit a greater support for the club owner than do the fans with relatively more stable jobs or the ones with relatively higher income. A passing conclusion might have led us to think that less economically well-off people are "rural", "poor", or "stupid", such that they fall victim to a new marketing ploy for this new political product. However, when also carefully considering the changes in Thailand's political landscapes in the past few decades, an understanding may be developed, with greater clarity, in regards to the interaction between the politician owners of the football clubs and this group of people, whom Nidhi Eoseewong (2007) calls "the lower middle class" or whom Apichart Satitniramai, Yuti Mukdawijit, and Niti Pawakaphan (2013) call "the new citizens".

For us, the data collected here can somewhat confirm that the fans have some favorable attitudes towards the politician owners of the club as well as some awareness that the owners have sacrificed for the goods and have a hand in developing and building a good reputation for the province. If the notions expressed by Eoseewong (2007: 6) and by Satitniramai, Mukdawijit, and Pawakaphan (2013: 56) are correct, then, at least in this preliminary conclusion, reasonable are their explanations that "[this group of people] desires a public policy which serves their benefits" and desires "changes" (while the more stable group of people have no such desire), such that the policy which are "tangible and edible" would have an effect on their attitudes and their political behaviors.

It is also visible that the new phenomenon has been born in the sport of football in Thailand from before where the clubs were all based in Bangkok and belonged to a government agency, a state enterprise, or a financial institution to now where the clubs belong to the local politicians (Panyakaew, Tongyukong, Sa-nguansak, \& Namprai, 2016: 186). The victory that used to belong to the Bangkok Bank Club (1996), the Air Force (1997 and 1999), Sintana (1998), BEC Tero Sasana (2000 and 2001/2002), Krungthai Bank (2003/2004), the Tobacco Monopoly's Employees (2004/2005), and Bangkok University (2006) has now become the victory for Chonburi F.C. (2007) and particularly Buriram United (2008, 2011, 2013, 2015, and 2017).

In regards to Buriram United in particular, with the unprecedented success, not only has it created pride for the people of Buriram, but Rattachart Tasanai and Woradech Chantarasorn (2016) have also mentioned at least two other developments in Buriram after a local politician like Newin Chidchob took over the executive position at the provincial football club. First, economically, the growth rates of gross provincial product and income per head have more than doubled and, second, in terms of tourism, Buriram has become among the top five most visited towns in Thailand, consistent with the findings of Polyiam and Buatham (2016). This makes Buriram move from a province that might have previously been overlooked in a plan to develop a major town in the upcountry (Panyakaew, Tongyukong, Sa-nguansak, \& Namprai, 2016: 187) to a province that serves as a model for a town development (Thairath, 2014).

Another interesting observation is that the length of fandom is negatively related to the political support given to the club owner. The correlation coefficient analysis, nonetheless, indicates that the length of fandom and the loyalty to the club are positively related $(r=.150)$. This means that even though the samples who have long been fans of the club exhibit a greater loyalty to the club, they may give less political support to the club owner. In this connection, therefore, a long-term problem for the politician owner of the football club is not about building or maintaining the loyalty to the club among fans, but rather about maintaining the political support given to himself or herself and to prevent it from subsiding with time.

Last, the research results which show that the loyalty to the football club are related to the political support given to the club owner confirms the hypothesis that the participation in the sport of football by the politicians and their kin, as the club executives, not only makes the football club a center of pride for people in the province (Sonphlay, 2016b: 121), but it also has the potential to, in fact, translate into the voting bloc for these politicians. This is consistent with Panyakaew, Tongyukong, Sa-nguansak, and Namprai (2016), Sonphlay (2016a), Matichon (2014), Daily News (2014), Komchadleuk (2016), as well as the research by Dousti, Godarzi, Asadi, and Khabiri (2012), Semino and Masci (1996), and Ranc (2009).

\section{References}

Brazier, C. (2009). Football... Small Issues that Shakes the World. Bangkok: Kobfai Publication Project.

Cochran, W. (1977). Sampling Techniques (3rd ed.). New York: John Wiley \& Sons.

Daily News. (2014). "Football" in the Front; "Politics" in the Back. Retrieved March 15, 2018, from 
www.dailynews.co.th/article/277848

Dousti, M., Godarzi, M., Asadi, H., \& Khabiri, M. (2012). Politics in Sport of Iran. International Journal of Sport Studies, 2(3), 136-146.

Eoseewong, N. (2008, August 25). Political System Adjustment. Matichon, 6.

Hinkle, D., William, W., \& Stephen, G. (1998). Applied Statistics for the Behavior Sciences (4th ed.). New York: Houghton Mifflin.

Komchadleuk. (2016). People in Politics and Thai Football. Retrieved March 15, 2018, from www.komchadluek.net/news/scoop/239048\#

Matichon. (2014). "Football and Politics" Studies of Football that Is No Longer Just a Sport. Retrieved March 15, 2018, from http://m.matichon.co.th/readnews.php?newsid=1405841673

Panyakaew, W., Tongyukong, A., Sa-nguansak, P., \& Namprai, P. (2016). Thailand's Premier League: Masculinity, Adolescence, and Culture of Consumerism. Chiang Mai: Faculty of Social Studies Research and Academic Service Institute, Chiang Mai University.

Polyiam, S., \& Buatham, O. (2016). The Role of Buriram United Football Club for Tourism Promotion in Buriram Province. Chophayom Journal, 27(1), 91-101.

Ranc, D. (2009). Local Politics, Identity and Football in Paris. Modern \& Contemporary France, 17(1), 51-65. https://doi.org/10.1080/09639480802639785

Satitniramai, A., Mukdawijit, Y., \& Pawakarapan, N. (2013). Review of Thailand's Political Landscape. Bangkok: Faculty of Economics, Thammasat University.

Semino, E., \& Masci, M. (1996). Politics is Football: Metaphor in the Discourse of Silvio Berlusconi in Italy. Discourse \& Society, 7(2), 243-269. https://doi.org/10.1177/0957926596007002005

Sonphlay, C. (2016a). The Roles of Thai Politicians in a Thai Football Club: Business or Politics. King Prajadhipok's Institute Journal, 14(2), 133-150.

Sonphlay, C. (2016b). Football, Upcountry Power, and Areas of New Culture. In W. Panyakaew (Ed.), Thailand's Premier League: Female, Power, Fan Culture, and New Class (pp. 121-139). Bangkok: Center for Gambling Studies, Faculty of Economics, Chulalongkorn University.

Srisa-ard, B. (2002). Basic Research (7th ed.). Bangkok: Suwiriyasarn.

Tantijariyapan, S. (2017). Political Support Networks of Local Politicians in Uttaradit Province. Local Administration Journal, 10(2), 1-16.

Tasanai, R. \& Chantarasorn, W. (2016). The Role of Buriram United Football Club in Developing Buriram Province. VRU Research and Development Journal: Humanities and Social Sciences, 11(2), 77-86.

Thairath. (2014). Buriram Model, A Model for Town Development. Retrieved March 15, 2018, from www.thairath.co.th/content/435963.

Tokmak, G. \& Aksoy, R. (2016). Factors Affecting Brand Loyalty in Football: An Application on "the Big Four" Football Clubs in Turkish Super League. International Review of Economics and Management, 4(3), 84-106. https://doi.org/10.18825/irem.01078

\section{Copyrights}

Copyright for this article is retained by the author(s), with first publication rights granted to the journal.

This is an open-access article distributed under the terms and conditions of the Creative Commons Attribution license (http://creativecommons.org/licenses/by/4.0/). 